\title{
Edutainment and Serious Games - Games Move into Professional Applications
}

\author{
José L. Encarnação \\ Chairman, INI-GraphicsNet Foundation \\ Professor, Technische Universität Darmstadt \\ Rundeturmstrasse 10 \\ 64283 Darmstadt \\ jle@inigraphics.net \\ http: //www.inigraphicsnet-stiftung.de/
}

\begin{abstract}
The talk will provide an overview of the symbiosis of Computer Graphics, Interactive Digital Storytelling and Entertainment technology as basis for Storytelling based Edutainment Applications and Serious Games for business and market oriented applications.

Since human age, stories have been told and used as media to document history and transmit personal experiences. In the digital age, Computer Graphics is used to build interactive virtual worlds for training and simulation, game and storytelling technologies are used to motivate learners and provide playful, story-driven information and communication environments. This is now starting to be used more and more for professional application, that means "using games on and for the job"!

Within the talk, underlying methods, concepts and technologies will be illustrated by current and recent projects of the INI-GraphicsNet in that domain: The "Virtuelles Autohaus" and "Virtual IGD Rostock" as examples for playful interactive virtual environments for training and simulation, "Virtual Human" and the "Servingo Story Generator" as examples for Storytelling based edutainment applications and "INSCAPE", "U-CREATE" addressing the authoring process for the creation of these edutainment scenarios and serious games for a given application domain.
\end{abstract}

